\title{
KETEPATAN PEMERIKSAAN RADIOLOGI DAN BTA APUSAN LANGSUNG DENGAN KULTUR DALAM DIAGNOSIS TUBERKULOSIS PARU DI MEDAN
}

\author{
Erfiyani $S^{*}$, Amira Permatasari Tarigan** \\ Dinas Kesehatan, Binjai, ${ }^{* *}$ Jurusan Keperawatan Poltekkes Kemenkes Medan
}

\begin{abstract}
Lung tuberculosis is one of transmitted diseases which are caused by Mycobacterium tuberculosis through nuclei droplet. Diagnosis for lung tuberculosis is usually detected by the examination of direct sputum removal, thorax photo, and Culture. The type of the research was descriptive study by using diagnostic test and the samples consisted of sputum and thorax photo. The sputum was taken accidentally, in the morning, and accidentally which was examined by using Ziehl Nelsen method and culture. The objective of the research was to find out the effectiveness of examining direct BTA removal and radiology which were compared with Culture. The samples were taken from Private Practice of Tuberculosis Specialists in Medan and in BP4, Medan which had fulfilled inclusive criteria, radiology examination and three times of phlegm taking for direct BTA removal and culture were performed; after that, radiology diagnostic test for direct BTA removal was compared with Culture. 60 samples on direct removal method indicated the value of sensitivity of $59.38 \%$, specificity of $92.86 \%$, value of positive prediction of $90.48 \%$, value of negative prediction of $66.7 \%$, ratio of positive likelihood of 8.31 , and ratio of negative likelihood of 0.44 . Radiology method indicated sensitivity of $62.63 \%$, specificity of $82.14 \%$, the value of positive prediction of $80.77 \%$, value of negative prediction of $67.65 \%$, ratio of positive likelihood of 3.67 , and ratio of negative likelihood of 0.42. Of the 21 samples, positive BTA which underwent minimum lung damage of 4 (6.7\%), moderate damage of $9(15.0 \%)$, and wide damage of $5(8.3 \%)$. The result of the research showed that radiology examination indicated that the value of sensitivity was higher than direct removal method, compared with culture as gold standard in BTA examination.That clinical benefit was bigger in direct removal method can be seen from the value of positive prediction which was higher than radiology method so that it is recommended that both examination techniques be used to diagnose lung tuberculosis.
\end{abstract}

Keywords : Direct BTARemoval, Radiology Compared with Culture

\section{PENDAHULUAN}

Tuberkulosis (TB) merupakan masalah kesehatan yang penting bagi kesehatan. Berdasarkan laporan WHO tahun 2010, terdapat 8,5 juta kasus baru tuberkulosis atau sama degan 128 kasus per 100.000 penduduk dan 1,2-1,5 juta kasus kematian per tahun.Wilayah Asia menanggung bagian yang terberat dari beban tuberkulosis paru global yakni sekitar 59\% dari kasus tuberkulosis paru di dunia. Jumlah kasus tertinggi pada 2011 adalahNegara India (2-2,5 juta), Cina (0,9-1,1 juta), Afrika Selatan (0,4-0,6juta), Indonesia (0,4-0,5juta) dan Pakistan (0,3-0,5 juta). ${ }^{1}$

Kasus TB di Indonesia bulan Mei 2010 tercatat 294.732 kasus dan telah diobati, serta lebih dari 169.213 diantaranya terdeteksi basil tahan asam (BTA) positif. $^{2}$

Hasil pendataan Dinas Kesehatan Propinsi Sumatera Utara tahun 2010, tercatat 73,8 persen penderita tuberkulosis paru BTA (+) atau sebanyak 15.614 orang. Hasil survey P2M Dinas Kesehatan Propinsi Sumatera Utara, Kota Medan merupakan yang terbesar penderitanya bila dibandingkan dengan jumlah penduduk dari tiap kabupaten/kota. Penderita suspek TB sebanyak 11.487 orang, dengan BTA (+) sebanyak 1.843 orang. ${ }^{3,4}$

Pemeriksaan paru tanpa pemeriksaan radiologi saat ini dapat dianggap tidak lengkap.Karena suatu penyakit paru belum dapat disingkirkan dengan pasti sebelum dilakukan pemeriksaan radiologi. Pemeriksaan BTA sebagai uji diagnosis belum dapat digantikan dengan uji laboratorium lain, sebenarnya metode ini kurang sensitif karena baru memberikan hasil positif bila terdapat $>10^{3}$ organisme/ml sputum. ${ }^{5}$ Sementara itu untuk mendapatkan kuman pada pemeriksaan kultur dibutuhkan jumlah sekitar 50-100 kuman/ml sputum. ${ }^{6}$ Metode kultur sendiri memiliki peran penting untuk menegakkan diagnosis TB karena sensitivitas dan spesifisitas lebih baik dari pada pewarnaan BTA.

\section{Tuberkulosis (TB) Paru Struktur dan morfologi}

Mycobacterium tuberculosis (M.TB) berbentuk batang, lurus atau sedikit melengkung tidak berspora dan tidak berkapsul. Bakteri ini berukuran lebar 0,3-0,6 mikron, panjang 1-4 mikron dinding M.tuberkulosis sangat 
kompleks terdiri dari lapisan lemak cukup tinggi (60\%). Penyusun utama dinding sel M.tuberculosis ialah asam mikolat, lilin kompleks, trehalosa dimikolat yang disebut cord factor dan mikobakterium sulfolipid yang berperan dalam virulensi. ${ }^{7,8}$

\section{Gejala klinik dan pemeriksaan fisik}

Keluhan umum yang dirasakan penderita TB diantaranya: batuk terus menerus dan berdahak selama 3 minggu atau lebih, demam, batuk darah, sesak nafas, nyeri dada, tidak ada nafsu makan, berat badan menurun, sakit kepala, meriang, nyeri otot, keringat malam dan lainlain. ${ }^{3}$ Pada umum TB paru yang dicurigai adalah bagian apeks, bila dicurigai adanya infiltrasi yang luas pada paru, maka suara perkusi akan redup dan pada auskultasi akan terdapat suara napas bronkhial juga suara tambahan berupa ronkhi basah, bila terdapat kavitas pada paru maka perkusi memberikan suara yang hipersonor dan auskultasi memberikan suara amforik. ${ }^{9}$

\section{Pemeriksaan RadiologiToraks}

Foto toraks digunakan untuk mendiagnosis banyak kondisi yang melibatkan dinding toraks dan struktur yang berada pada kavitas toraks termaksud paruparu dan jantung.Bagian paru yang paling sering terkena adalah bagian apikal dan segmen posterior lobus superiorkarena pada bagian apikal dan subapikal paru mempunyai tekanan oksigen lebih tinggi bila dibanding dengan tempat lain. Pada tekanan oksigen yang tinggi ini virulensi Mycobacteria dapat meningkat.Luasnya proses yang tampak pada foto toraks terdiri dari lesi minimal (minimal lesion), lesi sedang (moderat lesion) dan lesi luas (far advance). ${ }^{10}$

\section{Pemeriksaan BTA Mikroskopis}

Pemeriksaan sputum di laboratorium mikrobiologi diagnosis penyakit TB masih didasarkan pada pemeriksaan mikroskopis metode pewarnaan Zehl-Nielsen atau di kenal metode pewarnaan (Smear), yang mendeteksi basil kuman Mycobacterium Tuberculosis Complek (MTC).Walaupun telah banyak metode diagnosis TB yang telah dikembangkan, termaksud teknik molekuler, pewarnaan BTA apusan langsungdan kultur yang menggunakan media Lowenstein-Jensen (LJ) masih merupakan metode standart baku emas dalam mendiagnosis penyakit TB aktif. $^{11}$

Pemeriksaan mikroskopis apusan langsung dengan tahap pertama, pengumpulan specimen yaitu pengumpulan dahak yang berasal dari saluran napas bagian bawah berupa lendir yang berwarna kuning kehijauan (mukopurulen) pasien berdahak dalam keadaan perut kosong, sebelum makan dan minum dan membersihkan rongga mulut terlebih dahulu dengan berkumur air bersih. Tahap kedua yaitu pembuatan pembuatan apusan sputumdengan cara sediaan di atas kaca setelah kering lalu difiksasi diatas nyala api spritus Tahap ketiga yaitu pewarnaan dengan cara Ziehl Nielsendengan cara sediaan digenangi dengan asam alkohol (HCl-Alkohol 3\%) atau asam sulfat $25 \%$ sampai warna merah fuchsin hilang. Kemudian dibilas dengan air mengalir. Tetesin dengan methilin Blue 0,3\% sampai menutupi seluruh permukaan, diamkan selama 10-20 detik dan bilas dengan air mengalir, lalu dibiarkan kering di udara terbuka. Dengan pewarnaan Ziehl-Neelsen akan tampak berwarna merah dengan latar belakang biru. ${ }^{12,13}$,

\section{Kultur}

Kultur kuman merupakan cara pemeriksaan yang akurat karena memiliki sensitivitas dan spesifisitas tinggi (89.9\%) dan $100 \%$ sehingga dipakai sebagai diagnosis pasti tuberkulosis paru. Selain untuk mengidentifikasi kuman Mycobacterium, metode pemeriksaan kultur juga digunakan untuk menegakkan diagnosa tuberkulosis, sedangkan test resistansi kuman bermanfaat untuk terapi dimana sekarang ini sudah banyak kuman Mycobacterium yang resisten dengan obat anti tuberkulosis. Teknik kultur yang biasanya dipakai di laboratorium adalah Kultur pada media padat. ${ }^{14}$

\section{Desain penelitian}

Jenis penelitian ini adalah penelitian deskriptif dengan menggunakan uji diagnostik yaitu uji sensitifitas dan spesifisitas.

\section{Tempat dan waktu penelitian}

Rumah Sakit BP4 Medan dan Praktek Dokter Paru Swasta di Medan serta pemeriksaan dilakukan di Ruang Radiologi Paru BP4 dan Laboratorium Mikrobiologi Terpadu Fakultas Kedokteran USU selama 4 bulan mulai Juli-Oktober 2013.

\section{Tujuan penelitian}

1. Tujuan Umum

Mengetahui ketepatan pemeriksaan radiologi dan BTA apusan langsung dengan kultur dalam diagnosis tuberkulosis paru.

2. Tujuan Khusus

a. Mengetahui ketepatan nilai sensitivitas, spesifisitas, nilai ramal positif dan nilai ramal negatif pemeriksaan metode apusan langsung.

b. Mengetahui ketepatan nilai sensitivitas, spesifisitas, nilai ramal positif dan nilai ramal negatif pemeriksaan radiologi.

c. Mengetahui perbandingan ketepatan nilai sensitivitas, spesifisitas, nilai ramal positif dan nilai ramal negatif dari pemeriksaan radiologi dan BTA apusan langsung dengan kultur terhadap diagnosis tuberkulosis paru.

\section{Populasi dan Sampel}

Populasi adalah seluruh pasien suspek tuberkulosis di Kota Medan pada bulan Juli-Oktober 2013 dengan jumlah sampel sebanyak 60 orang berdasarkan rumus uji hipotesis satu sampel menurut Lemeshow. ${ }^{15}$ 
Kriteria Inklusi Sampel

a. Suspek dewasa ( $>15$ tahun)

b. Pasien TB paru yang belum pernah diobati dengan OAT atau sudah pernah memakai OAT kurang dari satu bulan.

c. Sputum penderita tidak bercampur darah.

\section{CARA KERJA}

\section{Pemeriksaan radiologi foto toraks}

Hasil pemeriksaan foto toraks bila terdapat lesi kelainan pada paru-paru maka pasien adalah kriteria pasien tuberculosis.

\section{Metode spusan langsung}

Ose dipanaskan sampai merah.selanjutnya didinginkan. Kemudian dimasukkan ke dalam botol berisi pasir alkohol $70 \%$ dan digoyang-goyangkan untuk melepaskan partikel yang melekat.Kembali ose dibakar sampai merah. Sedian fiksasi jangan terlalu lama di dilewatkan di atas api lampu spritus.Sedian digenangi dengan larutan carbol fuchsin $0,3 \%$ dan dipanaskan. Kemudian didinginkan dan dicuci.Sedian kemudian digenangi dengan asam alkohol (HCL alkohol 3\%) sampai warna carbol fuchsin hilang dan dicuci kembali. Kemudian sedian kembali digenangi dengan methylene blue 0,3\% sampai terbentuk latar belakang biru. kemudian diperiksa di bawah mikroskop perbesaran 1000 kali.

Hasil pemeriksaan berdasarkan standart International Union Against Tuberculosis and Lung Diseases (IUATLD) sesuai dengan standart WHO.

\section{Metode Kultur}

Sputum 1 bagian tambahkan dengan 2 bagian $\mathrm{NaOH} 4 \%$.Vortex sampai homogeny, selanjutnya centrifuse $3000 \mathrm{~g}$ selama 15 menit.Buang supernatant, tambahkan aquadest sampai tanda tertinggi.Centrifuse lagi $3000 \mathrm{~g}$ selama 15 menit dan buang supernatant.Inokulasi secukupnya $(100 \mu \mathrm{l})$ pada 2 media Lowensten-Jensen (LJ), kemudian ratakan pada permukaan media tutup botol Mac Cartney dan longgarkan (jangan rapat-rapat).Selanjutnya Selanjutnya disimpan dalam inkubator $37^{\circ} \mathrm{C}$.Mengamati pertumbuhan setiap minggu, negatif bila sampai minggu ke 8 tidak ada pertumbuhan.

\section{Analisis Data}

Analisa data secara deskriptif untuk melihat distribusi frekuensi dari variabel. Uji diagnostik dengan tabel $2 \times 2$, kemudian dihitung nilai sensitivitas, spesifitas, nilai ramal positif dan nilai ramal negatif, rasio kemungkinan positif dan rasio kemungkinan negatif.

\section{HASIL PENELITIAN}

\section{Karakteristik demografi}

Distribusi responden lebih banyakditemukan berumur 15-55 tahun 43 orang $(71,7 \%)$, kemudian kelompok umur $>55$ tahun 17 orang $(28,3 \%)$. Responden lebih banyaklaki-laki 43 orang (71,7\%), dan perempuan 17 orang $(28,3 \%)$. Responden lebih banyaksuku Batak 32 orang (53,3\%), suku Jawa 23 orang (38,3\%), suku Aceh sebanyak 2 orang $(3,3 \%)$ dan minoritas suku Melayu, Minang dan Nias dimana frekuensi masing-masing sebanyak 1 orang $(1,7 \%)$.

Responden lebih banyak bekerja sebagai wiraswasta 24 orang $(40,0 \%)$, IRT 13 orang $(21,7 \%)$, pensiunan 7 orang $(11,7 \%)$, karyawan/pegawai swasta 5 orang (8,2\%), PNS/POLRI dan Pelajar/Mahasiswa masing-masing 4 orang $(6,7 \%)$, dan yang bekerja sebagai buruh/petani 3 orang $(5,0 \%)$.

Responden lebih banyak berpenghasilan Rp. 1.000.000-3.000.000 yaitu 41 orang (68,9\%), berpenghasilan lebih kecil dari Rp. 1.000.000 yaitu 10 orang $(16,7 \%)$, dan responden minoritas berpenghasilan lebih besar Rp. 3.000 .000 yaitu 9 orang (15\%).

Deskriptif pemeriksaan BTA metode Apusan langsung Hasil pemeriksaan BTA metode apusan langsung temuan BTA $(+)$ paling banyak dari sampel sputum pagi 21 sampel $(35,0 \%)$, kemudian sampel sputum sewaktu pertama 19 sampel $(31,7 \%)$ dan yang paling sedikit adalah sampel sputum sewaktu kedua 17 sampel $(28,3 \%)$.

Tabel 1. Hasil Pemeriksaan BTA Metode Apusan Langsung (Sewaktu, Pagi, Sewaktu)

\begin{tabular}{lccc}
\hline Hasil BTA & \multicolumn{3}{c}{ Metode Apusan Langsung } \\
\cline { 2 - 4 } & $\begin{array}{c}\text { Sewaktu } \\
\text { n }(\%)\end{array}$ & $\begin{array}{c}\text { Pagi } \\
\text { n }(\%)\end{array}$ & $\begin{array}{c}\text { Sewaktu } \\
\text { n }(\%)\end{array}$ \\
\hline Positif & $19(31,7)$ & $21(35,0)$ & $17(28,3)$ \\
Negatif & $41(68,3)$ & $39(65,0)$ & $43(71,7)$ \\
\hline Total & $\mathbf{6 0}(\mathbf{1 0 0 , 0})$ & $\mathbf{6 0}(\mathbf{1 0 0 , 0})$ & $\mathbf{6 0}(\mathbf{1 0 0 , 0})$ \\
\hline
\end{tabular}

Deskriptif pemeriksaan BTA metode radiologi

Hasil pemeriksaan metode radiologi menggunakan sputum pagi ditemukan radiologi positif 26 sampel $(43,3 \%)$ dan radiologi negatif 34 sampel $(56,7 \%)$.

Tabel 2. Hasil Pemeriksaan BTA dengan Metode Radiologi

\begin{tabular}{lcr}
\multicolumn{1}{c}{$\begin{array}{c}\text { Pemeriksaan Radiologi } \\
\text { (Luas Lesi) }\end{array}$} & Frekuensi & \% \\
\hline Radiologi Negatif & 34 & 56,7 \\
Lesi Minimal & 5 & 8,3 \\
Lesi Sedang & 13 & 21,7 \\
Lesi Luas & 8 & 13,3 \\
\hline \multicolumn{1}{c}{ Total } & $\mathbf{6 0}$ & $\mathbf{1 0 0}$ \\
\hline
\end{tabular}

Perbandingan metode apusan langsung (pagi) dengan pemeriksaan radiologi

Hasil pemeriksaan BTA menggunakan metode apusan langsung ditemukan BTA (+) lebih banyak pada sampel sputum pagi 21 sampel $(35,0 \%)$, kemudian sampel sputum sewaktu pertama 19 sampel $(31,7 \%)$ dan yang lebih sedikit pada sampel sputum sewaktu kedua 17 sampel $(28,3 \%)$. Kondisi menggambarkan pengambilan sputum pada pagi lebih banyak ditemukan BTA positif dibandingkan dengan sewaktu pertama, dan sewaktu kedua. 
Tabel 3. Hasil Pemeriksaan BTA Apusan Langsung Sputum Pagi dengan Metode Radiologi

\begin{tabular}{cccc}
\hline \multirow{2}{*}{$\begin{array}{c}\text { Apusan } \\
\text { Langsung }\end{array}$} & \multicolumn{2}{c}{ Radiologi } & Total \\
\cline { 2 - 3 } & \multicolumn{2}{c}{+} & \\
\cline { 2 - 3 } & $\mathbf{n ( \% )}$ & $\mathbf{n ( \% )}$ & $\mathbf{n}(\boldsymbol{\%})$ \\
\hline+ & $18(30,0)$ & $3(5,0)$ & $21(35,0)$ \\
- & $8(13,3)$ & $31(51,77)$ & $39(65,0)$ \\
\hline Total & $26(43,3)$ & $34(56,7)$ & $60(100)$ \\
\hline
\end{tabular}

Pemeriksaan metode apusan langsung dengan sputum pagi diperoleh lesi yang lebih besar pada sputum BTA(+) dibandingkan dengan BTA(-) pada pemeriksaan yang sama. Keadaan ini terlihat dari 26 orang yang positif secara pemeriksaan radiologi diperoleh yang paling banyak dengan lesi sedang pada apusan langsung positif 9 orang $(34,6 \%)$ sedangkan pada lesi sedang dengan pemeriksaan apusan langsung negatif 4 orang $(15,4 \%)$.

Tabel 4. Uji Silang Antara Pemeriksaan Metode Apusan Langsung (Pagi) terhadap Pemeriksaan Radiologi (Luas Lesi)

\begin{tabular}{lccc}
\hline $\begin{array}{c}\text { Pemeriksaan } \\
\text { Radiologi (Luas } \\
\text { Lesi) }\end{array}$ & \multicolumn{2}{c}{$\begin{array}{c}\text { Pemeriksaan Metode } \\
\text { Apusan Langsung } \\
\text { (Sputum Pagi) }\end{array}$} & \multirow{2}{*}{ Total } \\
\cline { 2 - 3 } & + & - & \\
\hline Lesi Minimal & $4(15,4 \%)$ & $1(3,8 \%)$ & $5(19,2 \%)$ \\
Lesi Sedang & $9(34,6 \%)$ & $4(15,4 \%)$ & $13(50,0 \%)$ \\
Lesi Luas & $5(19,2 \%)$ & $3(11,5 \%)$ & $8(30,8 \%)$ \\
\hline \multicolumn{1}{c}{ Total } & $\mathbf{1 8 ( 6 9 , 2 \% )}$ & $\mathbf{8 ( 3 0 , 8 \% )}$ & $\mathbf{2 6 ( 1 0 0 , 0 \% )}$ \\
\hline
\end{tabular}

Deskriptif pemeriksaan BTA Metode kultur

Hasil pemeriksaan metode kultur menggunakan sputum pagi lebih banyak ditemukan BTA positif 32 sampel $(53,3 \%)$ dan lebih sedikit BTA negatif 28 sampel $(46,7 \%)$.

Tabel 5. Hasil Pemeriksaan dengan Metode Kultur (Sputum Pagi)

\begin{tabular}{lcc}
\hline \multicolumn{1}{c}{ Hasil BTA } & \multicolumn{2}{c}{ Metode Kultur } \\
\cline { 2 - 3 } & n & \% \\
\hline Positif & 32 & 53,3 \\
Negatif & 28 & 46,7 \\
\hline Total & 60 & 100.0 \\
\hline
\end{tabular}

\section{Perbandingan Metode Apusan Langsung dan Kultur}

Hasil pemeriksaan BTA positif dengan metode apusan langsung adalah 21 sampel sputum dan BTA negatif 39 sampel. Sedangkan metode kulturditemukan BTA positif 32 sampel dan negatif 28 sampel.Dari 21 sampel yang positif secara apusan langsung diperoleh sebanyak 9,5\% (2 orang) sampel yang positif secara apusan langsung namun negatif secara kultur. Sedangkan dari sampel yang negatif secara apusan langsung ditemukan sebesar 33,3\% (13 orang ) positif secara kultur.

Hasil uji diagnosis antara pemeriksaan mikroskopis metode apusan langsung (Table 8) mempunyai sensitivitas sebesar 59,38\%, spesifisitas sebesar $92,86 \%$, nilai ramal positif sebesar $90,48 \%$ nilai ramal negatif sebesar $66,67 \%$, rasio kemungkinan positif sebesar 8,31 dan rasio kemungkinan negatif sebesar 0,44.

Tabel 6. Perbandingan Metode Apusan Langsung dan Kultur

\begin{tabular}{cccc}
\hline \multirow{2}{*}{$\begin{array}{c}\text { Apusan } \\
\text { Langsung }\end{array}$} & \multicolumn{2}{c}{ Kultur } & Total \\
\cline { 2 - 3 } & \multicolumn{2}{c}{+} & - \\
\cline { 2 - 3 } & $\mathbf{n ( \% )}$ & $\mathbf{n ( \% )}$ & $\mathbf{n ( \% )}$ \\
\hline+ & $19(90,5)$ & $2(9,5)$ & $21(100)$ \\
- & $13(33,3)$ & $26(66,7)$ & $39(100)$ \\
\hline Total & $32(53,3)$ & $28(46,7)$ & $60(100)$ \\
\hline
\end{tabular}

Hasil uji silang pemeriksaan radiologi (luas lesi) dengan metode kultur

Temuandari 26 orang BTA positif secara radiologi diperoleh sebanyak 5 orang BTA negatif secara kultur dan sebanyak 21 orang positif secara kultur. Dari 26 orang yang positif secara radiologi terbagi kedalam tiga kelompok yakni 5 orang $(8,3 \%)$ dinyatakan memiliki lesi minimal, 13 orang $(21,7 \%)$ dengan lesi sedang dan 8 orang $(13,3 \%)$ dengan lesi luas. Berdasarkan jumlah responden maka diperoleh lesi palingbanyak adalah radiologi dengan lesi sedang, dan paling sedikit adalah lesi minimal pada pemeriksaan radiologi. Namun apabila dibandingkan antara lesi terhadap pemeriksaan kultur maka akan diperoleh nilai paling tinggi adalah hasil pemeriksaan radiologi dengan lesi sedang 18,3\% (11 orang), pemeriksaan radiologi dengan lesi minimal 6,7\% (4 orang) dan radiologidengan lesi luas $10,0 \%$ (6 orang).

Tabel 7. Hasil Uji Silang Pemeriksaan Radiologi (Luas Lesi) dengan Pemeriksaan Metode Kultur

\begin{tabular}{|c|c|c|c|}
\hline \multirow{2}{*}{$\begin{array}{c}\text { Pemeriksaan Radiologi } \\
\text { (Luas Lesi) }\end{array}$} & \multicolumn{3}{|c|}{ Kultur } \\
\hline & Positif & Negatif & Total \\
\hline Radiologi Negatif & $11(18,3 \%)$ & $23(38,3 \%)$ & $34(56,7 \%)$ \\
\hline Lesi Minimal & $4(6,7 \%)$ & $1(1,7 \%)$ & $5(8,3 \%)$ \\
\hline Lesi Sedang & $11(18,3 \%)$ & $2(3,3 \%)$ & $13(21,7 \%)$ \\
\hline Lesi Luas & $6(10,0 \%)$ & $2(3,3 \%)$ & $8(13,3 \%)$ \\
\hline Total & $32(53,3 \%)$ & $28(46,7 \%)$ & $60(100 \%)$ \\
\hline
\end{tabular}

Hasil uji diagnostik metode apusan langsung dan radiologi terhadap kultur

Kemampuan pemeriksaan metode radiologi dalam mendiagnosis tuberkulosis paru 3,25\% lebih tinggi dibandingkan apusan langsung yang artinya bahwa metode radiologi ini mampu mendeteksi diantara penderita TB adalah sebesar 3,25\% lebih tinggi dari apusan langsung.

Spesifisitas pemeriksaan radiologi lebih rendah $10,72 \%$ dari BTA apusan langsung, hal ini menunjukkan bahwa kemampuan pemeriksaan radiologi untuk menyingkirkan subjek yang tidak menderita tuberkulosis paru 10,72\% lebih rendah dari metode apusan langsung.

Nilai ramal positif menunjukkan besarnya peluang subjek menderita tuberkulosis paru bila hasil pemeriksaannya positif, dalam penelitian ini pemeriksaan BTA apusan langsung memberikan manfaat klinis dalam penegakan kasus tuberkulosis sebesar 9,71\% lebih besar dari radiologi. Hal ini dapat disebabkan oleh beberapa hal diantaranya kesalahan dalam pembacaan hasil foto atau 
dapat juga kesalahan dari tenaga radiologi dalam tehnik pengambilan foto sehingga memberi hasil yang negatif.

Nilai ramal negatif menunjukkan besarnya peluang subjek tidak menderita TB paru bila hasil BTA negatif dalam penelitian ini diperoleh bahwa nilai ramal negaif metode apusan langsung lebih rendah 0,98\% dibandingkan radiologi, sehingga dapat disimpulkan bahwa kemampuan untuk menentukan subjek dan tidak sakit dari total subjek yang negatif lebih baik pada metode radiologi dibandingkan metode apusan langsung

Rasio kemungkinan positif lebih besar pada apusan langsung yakni 8,31 dibandingkan radiologi sehingga metode apusan langsung lebih kuat menunjukkan hubungan antara hasil test positif dengan keadaan seseorang yang benar-benar sakit dibandingkan metode radiologi. Ratio kemungkinan negatif di dapat pada metode apusan lansung sebesar 0,44 dan radiologi adalah 0,42 artinya kemampuan seseorang untuk tidak sakit jika hasil ujinya negative adalah tinggi tinggi LR- $\leq 1$.

Tabel 8. Hasil Uji diagnostik Metode Apusan Langsung dan Radiologi terhadap Kultur

\begin{tabular}{lcc}
\hline \multicolumn{1}{c}{ Pemeriksaan } & $\begin{array}{c}\text { Metode Apusan } \\
\text { Langsung } \\
(\mathbf{\% )}\end{array}$ & $\begin{array}{c}\text { Metode } \\
\text { Radiologi } \\
(\mathbf{\%})\end{array}$ \\
\hline Sensitifitas & $59,38 \%$ & $62,63 \%$ \\
Spesifisitas & $92,86 \%$ & $82,14 \%$ \\
Nilai ramal positif & $90,48 \%$ & $80,77 \%$ \\
$\begin{array}{l}\text { Nilai ramal negatif } \\
\text { Rasio kemungkinan } \\
\text { positif }\end{array}$ & $66,67 \%$ & $67,65 \%$ \\
$\begin{array}{l}\text { Rasio } \\
\text { negatif }\end{array}$ & 8,31 & 3,67 \\
\hline
\end{tabular}

\section{DISKUSI}

\section{Karakteristik responden}

Subjek penelitian YAITU ini diperoleh mayoritas responden berumur 15-55 tahun 43 orang dan kelompok umur $>55$ tahun 17 orang, dengan insiden terbesar pada kelompok umur 41-59 tahun 25\%. Penelitian Hiswani ${ }^{16}$ didapatkan penyakit TB paru paling sering pada usia muda (usia produktif) 15-59 tahun, dengan terjadinya transisi demografi.Pada usia lanjut yaitu lebih dari 55 tahun penyebabnya adalah sistem immonologis yang menurun sehingga sangat rentan terhadap berbagai penyakit termaksud penyakit TB. Data Riskesdas $(2007)^{17}$ diketahui prevalensi TB paru cendrung meningkat sesuai dengan bertambahnya umur dan prevalensi tertinggi pada usia lebih dari 65 tahun

Responden lebih banyak laki - laki 43 orang $(71,7 \%)$ dan perempuan 17 orang $(28,3 \%)$. Haryono dalam Helper Sahat Manalu ${ }^{18}$ mendapatkan penderita TB paru lebih banyak laki-laki 54,5\% dibandingkan perempuan $45,5 \%$, Long ${ }^{19}$ melaporkan prevalensi TB Paru dua pertiga pada laki-laki dan sepertiganya perempuan, Yueng dkk $(2002)^{20}$ mendapatkan prevalensi pada laki-laki $65,7 \%$ dan perempuan $30,3 \%$ di Hongkong. WHO juga menyatakan angka kejadian TB lebih besar pada laki-laki disebabkan karena laki-laki dewasa lebih sering melakukan aktivitas sosial. $^{1}$
Berdasarkan suku bangsa diperoleh Batak sebanyak 32 orang $(53,3 \%)$ karena mayoritas responden yang datang ke BP4 dan Praktek Dokter Paru Swasta bersuku Batak. Hal ini didukung oleh data statistik dari Badan Pusat Statistik Kota Medan bahwa suku Batak presentasi penduduknya di Kota Medan menempati urutan kedua yaitu sebesar $21 \%$.

Status pekerjaan terbanyak pada wiraswasta termaksud didalamnya pedagang, sebanyak 24 orang (40\%) dengan penghasilan terbesar 1-3 juta $(68,9 \%)$, Hiswani $^{21}$ menyatakan faktor sosial ekonomi dengan keadaan rumah dan kepadatan serta lingkungan tempat kerja yang buruk dapat menyebabkan penularan TBC pendapatan keluarga juga sangat erat juga dengan penularan TB karena pendapatan yang kecil membuat orang tidak layak untuk memenuhi syarat-syarat kesehatan. Pradono $^{22}$ dalam penelitiannya menyatakan bahwa keluarga yang mempunyai pendapatan yang lebih tinggi akan lebih mampu menjaga kebersihan lingkungan, penyediaan air minum membeli makanan yang memadai serta mampu membiayai pemeliharaan kesehatan yang mereka perlukan.

\section{Ketepatan pemeriksaan BTA metode apusan langsung dan radiologi terhadap kultur}

Luas lesi pemeriksaan radiologi menunjukkan jumlah sampel yang sputumnya positif mengandung kuman $M$. tuberculosis dan mengalami lesi paru yang minimal $6,7 \%$ (4 orang), jumlah sampel yang positif mengandung kuman $M$. tuberculosis dan mengalami lesi sedang 15,0\% (9 orang) dan jumlah sampel yang positif mengandung kuman M.tuberculosis dan mengalami lesi luas $8,3 \%$ (5 orang) dari total sampel yang positif. Sampel yang sputumnya negatif mengandung kuman M.tuberculosis mengalami lesi minimal 1,7\% (1 orang) dan jumlah sampel yang sputumnya negatif mengandung kuman M.tuberculosis mengalami lesi sedang 6,7\% (4 orang) dan lesi luas 5,0\% (3 orang). Hasil tersebut menunjukkan jumlah sampel diperoleh yang paling banyak adalah pada lesi sedang. Pada radiologi positif sebanyak $15,0 \%$ (9 orang), sedangkan pada lesi sedang dengan pemeriksaan radiologi negatif 6,6\% (4 orang).

Sejalan dengan penelitian Nurjihad $^{23}$ di RS Persahabatan Jakarta yang menunjukkan jumlah sampel yang sputumnya positif mengandung kuman BTA dan mengalami lesi paru yang minimal adalah 23,1\% (21 orang), jumlah sampel yang positif mengandung kuman BTA dan mengalami lesi sedang adalah 39,5\% (36 orang) dan jumlah sampel yang positif mengandung kuman BTA dan mengalami lesi luas adalah 37,4\% (34 orang), dalam hal ini penelitian ini juga mendapat hasil yang lebih banyak pada gambaran paru lesi sedang .

Berbeda dengan penelitian Soesanti ${ }^{24}$ menunjukkan jumlah sampel BTA dan mengalami lesi luas 7 orang (14\%) lesi sedang sebanyak 13 orang (26\%) dan lesi minimal sebanyak 20 orang (40\%). Mulyadi ${ }^{25}$ di RSUDZA Banda Aceh yang mendapatkan hasil radiologi dari BTA positif dari jumlah sampel 34 orang dengan gambaran lesi luas sebanyak 16 orang $(47,1 \%)$, lesi sedang 12 orang $(35,3 \%)$ dan lesi minimal 6 orang $(17,6 \%)$, Penelitian 
Laurensius $^{26}$ di UP4 Propinsi Kalimantan Barat mendapatkan luas lesi dari BTA positif dari 34 sampel didapat lesi minimal 3 orang $(8,8 \%)$, lesi Sedang 12 orang $(35,9 \%)$ dan lesi luas 19 orang $(55,9 \%)$. Penelitian Hilaluddin $^{27}$ ditemukan lesi yang paling banyak adalah lesi luas 30 orang $(44,1 \%)$, lesi minimal 20 orang $(29,4 \%)$, lesi minimal 18 orang $(26,4 \%)$.

Hubungan antara tingkat kepositifan BTA dan radiologi toraks terhadap kultur didapat hasil analisis data dari 26 orang penderita TB paru yang positif diperoleh lesi minimal 4 orang $(6,7 \%)$, lesi sedang 9 orang $(15,0 \%)$ dan lesi luas 5 orang $(8,3 \%)$ sedangkan pada pemeriksaan apusan langsung negatif didapati lesi minimal 1 orang $(1,7 \%)$, lesi sedang 4 orang $(6,7 \%)$ dan lesi luas 3 orang $(5,0 \%)$. Hasil penelitian ini hampir sama dengan penelitian Khair $^{28}$, membuktikan tidak terdapat hubungan yang signifikan antara hasil pemeriksaan sputum BTA dengan gambaran foto toraks pada penderita tuberkulosis paru.Penelitian Mulyadi dkk ${ }^{25}$ di RSUZA Banda Aceh juga mendukung bahwa dari 15 orang BTA positif terdapat lesi luas $57,1 \%$ dan pada BTA negatif juga di jumpai kelainan radiologi lesi luas $20 \%$.

Dalam penelitian ini memperlihatkan TB paru dengan hasil sputum BTA negatif juga didapatkan lesi sedang dan lesi luas secara radiologi. Secara teori apabila dijumpai lesi luas secara radiologi seharusnya sputum BTA positif dan berpotensi menular ${ }^{25}$. Shabir dalam Laurensius $^{26}$ melaporkan bahwa BTA positif menggambarkan jumlah bakteri yang lebih banyak pada lesi paru dibandingkan dengan jumlah bakteri pada BTA negatif.Terdapat korelasi yang kuat dan searah antara tingkat kepositipan BTA dan luas lesi radiologi yang disimpulkan semakin luas lesi pada gambaran radiologi maka semakin tinggi tingkat kepositipan BTA.

Pemeriksaan radiologi sendiri merupakan salah satu pemeriksaan yang di perlukan dalam menegakkan diagnosis TB paru pada pasien dengan BTA negatif selain itu juga untuk menilai kerusakan struktur paru yang diakibatkan oleh kuman TB. Namun sama seperti pemeriksaan BTA pemeriksaan radiologi juga mempunyai kekurangan.Ismail ${ }^{29}$ menyatakann manisfestasi radiologi pada pasien TB paru bersifat atipikal. Kelainan radiologi pada TB paru mempunyai kemiripan dengan penyakit paru lainnya seperti kelainan paru yang disebabkan oleh jamur karena lesi yang paling sering ditemukan di lapangan atas paru disertai pembetukan lubang (kavitas) selain itu lesi TB paru juga menyerupai infiltrant dan berbentuk bercakbercak menyerupai sarang tuberkulosis, ${ }^{9}$ sehingga pada penelitian ini sebaiknya pemeriksaan radiologi juga harus ditunjang dengan pemeriksan BTA dalam mendiagnosis TB paru.

Dari penelitian-peneliatin di atas lesi minimal pada kepositipan BTA lebih sedikit dibandingkan dengan lesi sedang dan lesi luas ini disebabkan karena pada awal gejala penyakit pasien mengeluh batuk, cendrung terlambat meminta pertolongan sarana kesehatan dibanding keluhan selain batuk, sedangkan keluhan batuk sering dianggap keluhan biasa yang dapat sembuh sendiri atau karena pengaruh rokok atau debu pada penelitian Sabrina ${ }^{30}$ di RS Dr M Djamil Padang mendapat hasil tahun 1998-2002 mencapai 52,94\% dari seluruh pasien yang dirawat, BTA sputum positif didapat pada $30,54 \%$ pasien dan lesi luas secara radiologi $89,13 \%$ dari data diatas dapat dilihat kasus TB yang dirawat cukup tinggi dengan lesi luas penyebab dari terjadinya keadaan tersebut dapat dikarenakan keterlambatan pasien dalam berobat atau keterlambatan dalam mendiagnosis.

\section{KESIMPULAN}

1. Tuberculosis Report. Geneva: WHO;2012.p 17.

2. Menteri Kesehatan RI. Rencana Aksi Nasional: Informasi Strategi Nasional Pengendalian TB Indonesia 2011-2014. Direktorat Jenderal Pengendalian Penyakit dan Penyehatan Lingkungan. Jakarta; 2011.

3. Departemen Kesehatan RI.Keputusan Menteri Kesehatan Republik IndonesiaNo. 364/MENKES/SK/V/2009 tentang Pedoman Penanggulangan Tuberkulosis (TB)Menteri Kesehatan Republik Indonesia. Jakarta: 2009.

4. Raunak P, Gita N, Swapna K, Vijay K, Preeti. Time to Sputum Conversion in Smear Positive Pulmonary TB Patients on Category I DOTS and Factors Delaying it. 2012: Vol. 60: 22-26.

5. Muzaffar R, Batool S, Azis A, Naqvi A, Rizvi A. Evaluation of the fastplaquetb Assay for Direct Infection of Mycobacterium tuberculosis in Sputum Specimens. Int J Tuberc Lung Dis. 2002; 6(7): 635-40.

6. Grange JM. Micobacterium in : Greenwood David, Slack RC, Peutheres JF, Medical. Microbiology, 16 ed, Chruchill Livingstone2002.

7. Zulfikri A. Buku Ajar Penyakit Dalam. Edisi V, Jilid III, Jakarta: Internapublishing 2009.

8. Yunus, F dkk. Pulmonologi Klinik, Jakarta, Bagian Pulmonologi Fakultas Kedokteran Universitas Indonesia. Jakarta: 2002.

9. Rasad. Tuberkulosis Paru In : Rasad Kartoleksono S, Ekayuda eds. Radiologi Diagnosis FK-UI Jakarta 2000.p. 126 - 139.

10. Salman KF. Lembar Fakta Tembagaku dan Tuberkulosis, Merokok Meningkatkan Resiko Timbulnya Penyakit Tuberkulosis (TBC), Jakarta: Puspaswara 2005.

11. Perkumpulan Pemberantasan Tuberkulosis Indonesia. Pedoman Diagnosis \& Penatalaksanaan Tuberkulosis di Indonesia. Jakarta: 2011.

12. Departemen Kesehatan RI. Pedoman Penanggulangan Tuberkulosis, Edisi 2, Cetakan PertamaJakarta: 2007.

13. Departemen Kesehatan RI.Keputusan Menteri Kesehatan Republik IndonesiaNo. 364/MENKES/SK/V/2009 Tentang Pedoman Penanggulangan Tuberkulosis (TB)Menteri Kesehatan Republik Indonesia.Jakarta : 2009.

14. Yoga, TA. Masalah Tuberkulosis Paru dan Penanggulangannya, Jakarta: Universitas Indonesia; 2005. 
15. Lemeshow $\mathrm{S}$, et al. Besar Sampel dalam Penelitian, Yogyakarta: Gajah Mada University Press; 1997.

16. Hiswani, Tuberkulosis Merupakan Penyakit Infeksi yang Masih Menjadi Masalah Kesehatan Masyarakat. 2011.

17. Badan Penelitian dan Pengembangan Kesehatan. Riset Kesehatan Dasar (RISKESDAS) 2007. Kementrian Kesehatan Republik Indonesia. Jakarta: 2007.

18. Helper Sahat Manalu dkk. Penelitian Mengenai Faktor Sosial Budaya yang Mempengaruhi Ketaatan Berobat Penderita TB Paru. Laporan Penelitian Pusat Penelitian Pengembangan Ekologi dan Status Kesehatan Badan Litbagkes Kementrian Kesehatan RI. Jakarta: 2004.

19. Long NH, Joansson E, Lonnroth K, Erikson B, Winkvist A, Diwan VK Longger delays In Tuberculosis among women in Vietnam 1999; 3:388-39

20. Yueng MC, Noerdjojo $\mathrm{K}$, Tan J, Tam M, Tuberculosis in the eldery in Hongkong 2002; 6:771-9.

21. Hiswani, Tuberkulosis Merupakan Penyakit Infeksi yang Masih Menjadi Masalah Kesehatan Masyarakat. 2011.

22. Pradono, Kesehatan dalam Pembangunan Berkelanjutan, Jurnal Arkeologi Kesehatan. Vol 6 No 2 Agustus 2007.

23. Nurjihad A, Soepandi PZ, Nawas A, Jusuf A, Bachtiar A. Perbandingan Akurasi Pemeriksaan Mikroskopis Apusan BTA Sputum 3 Kali Pagi (PPP) dan Sewaktu (SPS) pada Penderita
Tuberkulosis Paru di RS Persahabatan. Jurnal Respir Indo 2003: 23(3):161-70.

24. Soesanti Inne. Hubungan Antara Hasil Pemeriksaan Mycobakterium Tuberkulosis dengan Hasil Pemeriksaan Foto Rongen pada Penderita TB Paru di RS Paru Pamekasan Madura. 2006.p. 1-7.

25. Mulyadi dkk. Hubungan Tingkat Kepositipan Pemeriksaan Basil Tahan Asam (BTA) dengan Gambaran Luas Lasi Radiologi Toraks Pada Penderita Tuberkulosis Paru yang Dirawat di SMF Pulmonologi RSUDZA Aceh. 2011. p.133-135.

26. Laurensius Ivan Pentakosta. Hubungan Hasil Pemeriksaan Sputum Basil Tahan Asam (BTA) dengan Gambaran Luas Lasi Radiologi pada Pasien Tuberkulosis Paru di UP4 Provinsi Kalimantan Barat 2011-2012.

27. Hilaluddin S. Hubungan Pemeriksaan Dahak Dengan Kelainan Radiologis Pada Penderita TBC Paru Dewasa FK USU 2005.

28. Khair F. Hubungan Antara Hasil Pemeriksaan Sputum BTA (Basil Tahan Asam) dengan Gambaran Foto Thorax pada Penderita Tuberkulosis Paru di RS PKU (Pembina Kesejahteraan Umat) Muhammadiyah Surakarta. Fakutas Kedokteran Muhammadiyah Surakarta. 2010.

29. Ismail Y. Pulmonary Tuberculosis-A Review of Clinical Features and Diagnosis in 232 Cases. Medical Journal of Malaysia2004; 59(1): 56 - 64.

30. Sabrina E. dkk. Keterlambatan Diagnosis Tuberkulosis Paru di RS Dr Djamil Padang. 2007. 